\title{
Digital Entrepreneurial Nest: Supporting Digitization of Healthcare at National Level in Montenegro
}

\author{
Milovan ROGANOVIĆ ${ }^{\mathrm{a}, 1}$, Ivana OGNJANOVIĆ ${ }^{\mathrm{b}}$, Ramo ŠENDELJ ${ }^{\mathrm{b}}$, Christoph \\ REICH $^{\mathrm{c}}$, Laszlo BOKOR ${ }^{\mathrm{d}}$, John MANTAS ${ }^{\mathrm{e}}$, Martina GOLOB ${ }^{\mathrm{f}}$, Nataša ŠIMŠIĆg, \\ Irena OROVIĆ ${ }^{\mathrm{h}}$, Tanja RADUSINOVIĆ ${ }^{\mathrm{i}}$, Jevto ERAKOVIĆ ${ }^{\mathrm{a}}$, and Nataša ŽUGIĆ ${ }^{\mathrm{j}}$ \\ ${ }^{a}$ Clinic for Neurology, Clinical Centre of Montenegro, Montenegro \\ ${ }^{\mathrm{b}}$ University of Donja Gorica, Montenegro \\ ${ }^{c}$ Hochschule Furtwangen University, Germany \\ ${ }^{d}$ Budapest University of Technology and Economics, Hungary \\ ${ }^{e}$ National and Kapodistrian University of Athens, Greece \\ ${ }^{f}$ Arctur, Slovenia \\ ${ }^{g}$ Comtrade System Integration, Serbia \\ ${ }^{h}$ University of Montenegro \\ ${ }^{i}$ Chamber of economy of Montenegro \\ ${ }^{j}$ Ministry of Health, Montenegro
}

\begin{abstract}
Health and health systems are not excluded from the influence of digitalization. In Montenegro, regarding the digitization process, when compared to other sectors, the health sector is lagging. In this poster presentation, we present an ambitious Erasmus+ DigN€ST project aimed on modernization of digitalization of healthcare system in Montenegro, as one of priority fields at national level.
\end{abstract}

Keywords. digitization of healthcare, eHealth, national level

\section{Introduction}

The strategic vision of development of Montenegro (MNE) is focused on increasing the economy's competitiveness. Montenegro is the only country in the Western Balkans that has adopted a Smart Specialisation Strategy. Amongst four priority areas that have been defined (energy and sustainable environment, sustainable agriculture and food value chain, sustainable and health tourism) ICT is a horizontal sector as it provides business and technological support to other priority sectors [1]. The aging of population, the rising burden of noncommunicable diseases, the influence of vested interests on behavioral risk factors and the sustainability of national health service are main problems in healthcare systems worldwide. Potentials of digital technologies should be used in the process of overcoming these problems [2].

\footnotetext{
${ }^{1}$ Corresponding author, Milovan Roganović, Clinic for Neurology, Clinical Centre of Montenegro, Montenegro, Ljubljanska bb, 81000 Podgorica, Montenegro; E-mail: milovan.roganovic@kccg.me.
} 


\section{Methods}

Erasmus+ project Digital Entrepreneurial Nest and Industry 4.0 in Montenegro (DigN€st) (https://dignest.me/) aims to modernize higher education institutions (HEIs) in terms of industry digitization. With the complexity of such a process in mind, as well as current standards and best practices at the EU level, and clearly identified priorities and initiatives at the national level, we decided to take a step-by-step approach of 'learning from others' (via peer review processes), 'making adopted to own HE system and S3 Strategy' (via review and benchmarking), and final implementation and evaluation. All these steps are planned to be implemented in 3 dimensions by several coherent actions: (i) establishment of formal links between HEIs and business/industry at national level in MNE with strong connections to EU leaders in digitization; (ii) modernization of HEIs by development of practical training schemes; (ii) raising awareness, promotion of digitization process and digitized technologies. The proposed methodology is clearly rooted in the Digitising European Industry (DEI) Initiative (2016) [3], which identifies the establishment of Digital Innovation Hubs (DIHs) as a critical component for its implementation, with clear recommendations within DEI Working Group 1 - DIHs: Mainstreaming Digital Innovation Across All Sectors (in June 2017) identifying priority actions required to move the initiative forward.

\section{Results}

The main outcome of the proposed approach is a newly established MNE ACADEMIC DIH with an innovative topology and structure: it has two first layer nodes: the Digital Entrepreneurial Nest at the University of Donja Gorica and the Digital Support Centre at the University of Montenegro. Both HEIs implement a set of services titled Digital Business Support, while the following two sets of services are shared by both HEIs: Digital Education, as well as Innovation and Collaboration. Strong collaboration with relevant healthcare system institutions will maximize the use of existing capacities and resources at HEIs. This will lead to the development of high-level digital solutions that will improve the quality of the MNE health system.

\section{Discussion}

The services available through MNE ACADEMIC DIH will enable healthcare system to access the latest knowledge, expertise and technology for testing and experimenting with digital innovations relevant to its products, processes and services. Key characteristics of this model are the following: maximisation of available resources, cooperation between key stakeholders at national level, sustainable support to innovations and use of best practices and relevant experience at global level, from both academia and health industry. The model will be implemented and evaluated during funding period2021-2024.

\section{References}

[1] S3 in Montenegro [Internet]. S3. 2020 [cited 2021Aug27]. Available from: https://www.s3.me/en/s3montenegro 
[2] Odone A, Buttigieg S, Ricciardi W, Azzopardi-Muscat N, Staines A. Public health Digitalization in Europe. European Journal of Public Health. 2019;29(Supplement_3):28-35.

[3] The digitising European industry initiative in a nutshell [Internet]. The Digitising European Industry initiative in a nutshell | Shaping Europe's digital future. [cited 2021Aug27]. Available from: https://digital-strategy.ec.europa.eu/en/library/digitising-european-industry-initiative-nutshell 